\title{
Rapid incremental closed traction reduction of cervical facet fracture dislocation: the Stoke Mandeville experience
}

\author{
Wail A. Ahmed ${ }^{1} \cdot$ Anitha Naidoo $^{1} \cdot$ Maurizio Belci $^{1}$
}

Received: 6 June 2018 / Revised: 27 June 2018 / Accepted: 6 July 2018

(c) International Spinal Cord Society 2018

\begin{abstract}
Study design Retrospective case series study.

Objective To determine the success rate and neurological outcomes of rapid incremental closed traction reduction (RICTR) of cervical dislocations with spinal cord compression in the National Spinal Injuries Centre (NSIC), between June 2006 and December 2011.

Setting Tertiary spinal injuries centre, Stoke Mandeville Hospital, UK.

Methods A list of cervical trauma patients who were admitted to NSIC between January 2006 and December 2011 was retrieved from the hospital's electronic records, consultant and admission logbooks. Patients, admitted within 7 days of cervical facet dislocation and spinal cord injury (SCI), were included. Retrospective data collection and analysis was done using a data collection form and an Excel spreadsheet.

Results Seventeen patients have met the eligibility criteria of the study. One patient was excluded because he only had nerve root symptoms. The procedure was successful in $44 \%$ of the cases. Eighty-six percent of patients in the successful RICTR group improved in their discharge motor index score (MIS), whereas $43 \%$ improved in their post-reduction MIS. Overall, $81 \%$ of the cohort had improvements in their discharge MIS.

Conclusion Our RICTR success rate was low compared to the reported average success rate in the literature, likely due to delays in admission. Neurological outcomes were favourable in the majority of patients at discharge. In our opinion, early admission and RICTR attempts could have improved the results and therefore we would recommend that RICTR procedures are done for suitable patients in the Emergency Departments of Major Trauma Centres (MTC).
\end{abstract}

\section{Introduction}

Lower cervical spine dislocations (C2/C3-C7/T1) are commonly associated with neurological impairments. Treating these injuries, with closed or open reduction, has occasionally resulted in neurological worsening [1]. Yet, many surgeons have traditionally recommended rapid incremental closed traction reduction (RICTR) of the cervical spine followed by a posterior spinal fixation [2].

It is reported that cervical facet dislocations result from flexion and distraction forces with or without rotational forces acting on the sub-axial cervical spine [2]. Bilateral

Wail A. Ahmed

wail.ahmed2@nhs.net

1 National Spinal Injuries Centre, Stoke Mandeville Hospital, Aylesbury, UK facet dislocations are more commonly associated with neurological deficit compared with unilateral facet dislocations, which are often associated with nerve root injury or even no deficit [2]. Despite being uncommon, facet fracture dislocations are associated with a high incidence of severe neurological morbidity and present difficult management problems [3].

Similar to acute traumatic brain injury, the pathophysiology of the resulting spinal cord injury (SCI) involves a primary mechanical injury that disrupts the axons, blood vessels and cell membranes followed by a secondary injury involving oedema, ischaemia, electrolyte shift, free radical production, inflammation and delayed apoptotic cell death [4].

According to Norrell [5], the treatment of all spinal injuries is directed at: (a) preservation of functional and anatomic continuity of the spinal cord and nerve roots; (b) restoration of the spinal canal alignment to relieve neural compression; (c) establishment of spinal stability which will provide freedom from post-injury pain or delayed 
progression of neurologic signs; and (d) restoring the patient as quickly as possible to the highest level of function dictated by his/her neurologic status. In order to fulfil these goals in cervical facet dislocations, reduction of the spine is required to obtain solid healing of the injured tissues [6]. However, the best way of treating these injuries is debatable as reduction may either be open or closed, similar to all skeletal fractures and dislocations. Open reduction can be achieved either through an anterior or posterior approach, whereas closed reduction may be achieved by incremental skull traction or by manipulation using either sedation or general anaesthetic [7]. Post-reduction stabilisation of the spine can be achieved with skull tongs or a halo ring, otherwise the dislocation can be fused surgically [7].

The practice of gradual reduction through incremental increases in traction weight has been well recognised following the introduction of skull tongs by Crutchfield in 1933 [8]. This is usually carried out in a sedated but conscious patient over a period of several hours. Prior to that, reduction was often carried out using closed manipulation with or without general anaesthesia as first described by Walton in 1893 [9]. Currently, the most commonly used device for skull traction is the tong design introduced by Gardner in 1973 [10]. Using this spring loaded tension device led to simple and reliable application of the tongs and it has been reported that they can readily tolerate 65 pounds of traction [10].

A previous study comparing manipulation under anaesthesia (MUA) versus rapid reduction of cervical dislocations under sedation suggested that early reduction in patients with neurological deficits gives the best chance of neurological recovery and that rapid traction is often more successful and safer than MUA [11].

The aim of this retrospective study is to report the success rate (percentage of patients with successful relocation) and neurological outcomes of RICTR practised in the NSIC between June 2006 and December 2011.

\section{Methods}

\section{Procedure}

\section{RICTR set-up}

Patients were admitted directly through the emergency department or referred from another hospital. Following initial resuscitation using Advanced Trauma Life Support protocol and confirmation of diagnosis using X-rays and computed tomography (CT) scans, patients were transferred immediately for RICTR, in intensive therapy unit (ITU) or the NSIC high dependency unit (HDU) where a cardiac monitor, resuscitation medication and equipment were readily available. Patients were transferred to a turning bed with full spinal precautions and logroll transfer. After checking the equipment, a traction set would be attached to the head of the bed. Gardner Wells tong (GWT), incremental weights and $\mathrm{C}$-arm $\mathrm{X}$-ray machine were made available to use. Usually, the team performing the procedure would consist of a spinal injuries consultant (and/or a specialist registrar), spinal HDU nurse, radiographer and anaesthetist (when done in ITU)

\section{RICTR procedure}

Patients were assessed neurologically using the International Standards for Neurological Classification of Spinal Cord Injury [12] to determine the pre-reduction neurological levels of injury (NLI), ASIA Impairment Scale (AIS) grade, motor index score (MIS) and sensory scores. X-rays and CT scans would be reviewed to determine the level of the skeletal injury, type of injury (bilateral or unilateral) and presence/absence of fractures. A verbal consent was obtained from the patient. After shaving the area of the scalp above the ears, a marker pen was used to locate insertion points for GWT pins which were below the temporal ridge and equator (widest portion of the skull), $1-2 \mathrm{~cm}$ above the external auditory canal. Local anaesthetic was then infiltrated into the skin and galea of the scalp over the marked areas and the two pins screwed into position. Analgesia and sedation were provided using morphine and midazolam (or diazepam) in divided doses as well as cyclizine to prevent emesis. Counter-traction was provided using shoulder straps aided by tilting the traction bed to a reverse Trendelenburg position. RICTR was started using $5 \mathrm{~kg}$ weighs followed by X-ray screening and clinical assessment of neurological levels. Incremental weights of $2-5 \mathrm{~kg}$ were added every 5-10 min depending on the relative position of the dislocated facets followed by X-ray screening and clinical assessment of neurological levels. When the facets started to unhinge, incremental traction was combined with flexion using blanket rolls or pillows to aid reduction. Once it was achieved, traction weights would be reduced to $10-20 \mathrm{~kg}$ and the neck would be extended by placing the roll or pillow underneath the shoulders. In cases of failed reduction, traction with minimal weight was applied until definitive operative management was done. RICTR endpoints were: (i) successful reduction; (ii) neurological deterioration (loss of motor or sensory levels); and (iii) over-distraction at the dislocation level with reduction failure.

\section{Patients}

A list of 61 cervical trauma patients, who were admitted to the NSIC between January 2006 and December 2011, was 
retrieved from the hospital's electronic records. A screening process by reviewing the images on Picture Archiving and Communication System (PACS) was done to identify the patients who had cervical dislocations and RICTR. This was coupled with directly retrieving cases from a consultant logbook and the admission room logbook. Patients were included if they were admitted within 7 days of injury with SCI as a result of cervical facet dislocation and underwent attempted RICTR. Patients were excluded if they had cervical SCI due to hyperextension injury, tear-drop or burst fractures or if they had cervical dislocations without evidence of SCI.

Following identification of SCI patients with cervical dislocations, who had RICTR, data were collected from paper medical notes, electronic medical notes and PACS into anonymous data collection forms. The data collected included patients' study IDs, age, sex, date and time of injury, mechanism of injury, type and level of dislocation, pre- and post-reduction NLI, AIS grades, MIS, procedure outcome, weight used, associated injuries/complications, and operative interventions done.

\section{Data analysis}

Retrospective data analysis was done using means, percentages, ratios and bar charts. The mean age, male to female ratio, levels and types of dislocations, causes of injury, mean time to reduction and mean follow-up were all determined. The success rate was calculated as the percentage of patients who had successful relocation, which was confirmed by fluoroscopy screening or X-ray. Neurological outcomes in the form of pre-reduction, postreduction and discharge NLI, AIS and MIS were analysed using bar charts for comparison.

\section{Results}

Seventeen patients underwent RICTR in the NSIC between June 2006 and December 2011. One patient was excluded because he did not have SCI (had nerve root symptoms only which resolved following successful RICTR). Sixteen patients (18 attempts of RICTR) were included in this study. Two patients had 2 attempts of RICTR on two different occasions. Male to female ratio was 13 to 3 . The mean age was 32 years (range: 16-56 years). The causes of injury were motor vehicle accidents (excluding motorcycles) in nine patients, falls in four patients and one patient each for motorcycle and bicycle accidents and one assault injury. The levels of injury were $\mathrm{C} 6 / \mathrm{C} 7$ dislocation in six patients; C7/T1 in four patients; C5/C6 in three patients and C4/C5 in three patients. There were no $\mathrm{C} 2 / \mathrm{C} 3$ or $\mathrm{C} 3 / \mathrm{C} 4$ dislocations in this series. Thirteen of these were bi-facet
Table 1 Comparison of participants' demographic data and baseline characteristics

$\begin{array}{lll}\text { All patients who } & \text { Successful } & \text { Unsuccessful } \\ \text { underwent } & \text { RICTR group } & \text { RICTR group } \\ \text { RICTR attempts } & & \end{array}$

\begin{tabular}{|c|c|c|c|}
\hline $\begin{array}{l}\text { Total number } \\
\text { of patients }\end{array}$ & 16 & 7 & 9 \\
\hline $\begin{array}{l}\text { Total number } \\
\text { of RICTR } \\
\text { attempts }\end{array}$ & 18 & 7 & 11 \\
\hline $\begin{array}{l}\text { Mean age in } \\
\text { years (range) }\end{array}$ & $32(17-56)$ & $31.5(17-56)$ & $32(16-44)$ \\
\hline \multicolumn{4}{|l|}{ Gender } \\
\hline Male & 13 & 6 & 7 \\
\hline Female & 3 & 1 & 2 \\
\hline \multicolumn{4}{|c|}{ Skeletal level of injury } \\
\hline $\mathrm{C} 4 / \mathrm{C} 5$ & 3 & 1 & 2 \\
\hline $\mathrm{C} 5 / \mathrm{C} 6$ & 3 & 2 & 1 \\
\hline $\mathrm{C} 6 / \mathrm{C} 7$ & 6 & 4 & 2 \\
\hline $\mathrm{C} 7 / \mathrm{T} 1$ & 4 & 0 & 4 \\
\hline \multicolumn{4}{|c|}{ Type of facet injury } \\
\hline Bi-facet & 13 & 5 & 8 \\
\hline Uni-facet & 3 & 2 & 1 \\
\hline \multicolumn{4}{|l|}{ Admission NLI } \\
\hline $\mathrm{C} 3$ & 1 & 1 & 0 \\
\hline $\mathrm{C} 4$ & 5 & 3 & 2 \\
\hline $\mathrm{C} 5$ & 5 & 2 & 3 \\
\hline $\mathrm{C} 6$ & 2 & 1 & 1 \\
\hline $\mathrm{C} 7$ & 2 & 0 & 2 \\
\hline $\mathrm{C} 8$ & 1 & 0 & 1 \\
\hline \multicolumn{4}{|c|}{ Admission AIS grade } \\
\hline A & 13 & 6 & 7 \\
\hline B & 1 & 1 & 0 \\
\hline $\mathrm{C}$ & 2 & 0 & 2 \\
\hline $\begin{array}{l}\text { Mean time to } \\
\text { RICTR } \\
\text { attempt in h } \\
\text { (range) }\end{array}$ & $26(4-90)$ & $26.5(6-90)$ & $25.6(4-80)$ \\
\hline $\begin{array}{l}\text { Mean follow- } \\
\text { up in months } \\
\text { (range) }\end{array}$ & $7.5(3-20)$ & $10(6-20)$ & $5(3-10)$ \\
\hline
\end{tabular}

dislocations and three were uni-facet. There were associated facet fractures in ten patients (five patients in each of the successful and unsuccessful RICTR groups). Thirteen patients presented with AIS grade A, one with AIS grade B and two with AIS grade C [Table 1].

RICTR was successful in seven patients (44\%), including one patient who had successful RICTR in the second attempt. Nine patients (56\%) had unsuccessful RICTR, including one patient who had two failed attempts [Table 1]. Five patients had RICTR attempts more than $30 \mathrm{~h}$ after injury. Eighty percent of these RICTR attempts were 
Table 2 Comparison of pre-RICTR and discharge AIS grades and injury time to reduction between successful and unsuccessful RICTR groups

\begin{tabular}{llll}
\hline \multicolumn{2}{c}{$\begin{array}{l}\text { Injury time to RICTR } \\
\text { attempt in hours }\end{array}$} & $\begin{array}{l}\text { Pre-RICTR AIS } \\
\text { grades }\end{array}$ & $\begin{array}{l}\text { Discharge AIS } \\
\text { grades }\end{array}$ \\
\hline Successful RICTR group & & \\
P7 & 6 & A & A \\
P6 & 10 & B & B \\
P3 & 11 & A & B \\
P5 & 16 & A & A \\
P2 & 23 & A & A \\
P4 & 30 & A & A \\
P1 & 90 & A & A \\
Unsuccessful RICTR attempts group & \\
P16 & 4 & A & A \\
P10 & 5 & A & A \\
P11 & 11 & A & A \\
P8 & 12 & A & A \\
P14 & 12 & A & B \\
P15 & 18 & A & A \\
P1 & 27 & A & A \\
P12 & 48 & A & A \\
P9 & 52 & C & D \\
P13 & 69 & C & D \\
P13 & 80 & C & D \\
\hline
\end{tabular}

unsuccessful. Post RICTR attempts, cervical alignment in all patients was maintained with traction using GWT until surgery. In the successful RICTR group, there was no loss of reduction prior to surgery.

Patients were followed up from their acute injury until their discharge from the NSIC. The mean follow-up was 7.5 months (range: 3-20 months). At discharge, $81 \%$ of this cohort of patients improved neurologically in the MIS. Two patients with unsuccessful RICTR died before their discharge.

Two patients had adverse events as a result of RICTR. One patient developed a scalp laceration as a result of displacement of the GWT pin during RICTR. In another patient, the traction cord snapped, however, no change of neurology resulted from that incident.

\section{Successful RICTR group}

The mean follow-up was 10 months (range: 6-20 months). The mean injury time to reduction was $26.5 \mathrm{~h}$ (range: $6-90 \mathrm{~h}$ ). The mean would be $13 \mathrm{~h}$ by excluding one patient which had his second RICTR attempt at $90 \mathrm{~h}$. Following RICTR, five patients had anterior cervical discectomy and fusion (ACDF) using plate and screws; one had posterior cervical decompression and fusion with bone graft; and only one was treated non-operatively. Operative fusion and fixation of those six cases was done to provide early fusion and prevent future long-term loss of reduction and subsequent deformities. The post-reduction MRI scan of the patient who was managed non-operatively showed satisfactory reduction and bony alignment of the spine, with no dislocated disc or cord signal change. In addition to that, following an informed consent, the patient opted for a nonoperative treatment option.

Only one out of seven patients improved one grade (A to B) in the AIS at discharge [Table 2]. Overall, in the successful RICTR group, $43 \%$ of patients improved in their post-RICTR MIS, whereas $86 \%$ improved in their discharge MIS [Fig. 1]. At discharge, three patients improved by one motor level; two patients improved by two motor levels; and one patient improved by four motor levels [Fig. 1]. One patient had significant deterioration in the post-reduction MIS, however, this proved to be transient as the same patient showed significant improvement in the discharge MIS [Fig. 1]. Examples of pre-reduction and post-reduction MRI images for three patients who underwent successful RICTR are provided [Figs. 2-4].

\section{Unsuccessful RICTR group}

The mean follow-up was 5 months (range: 3-10 months). The mean injury time to reduction was $25.6 \mathrm{~h}$ (range: 4-80 h). Operative reduction and fixation in this group was done to provide cord decompression with early fusion and prevent long-term loss of reduction and deformities. Six

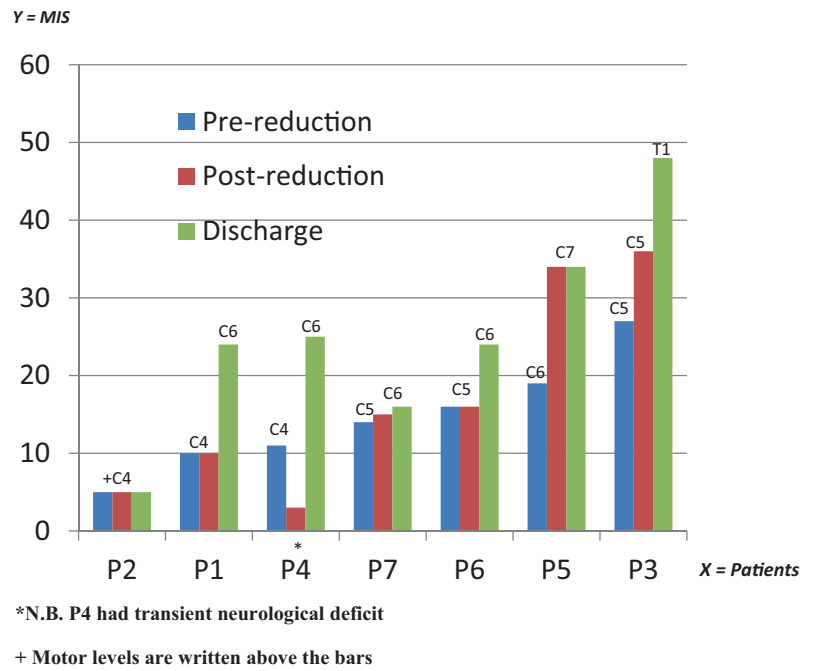

Fig. 1 Pre-reduction, post-reduction and discharge motor index scores (MIS) and motor levels for patients in the successful RICTR group. *N.B. P4 had transient neurological deficit. +Motor levels are written above the bars 


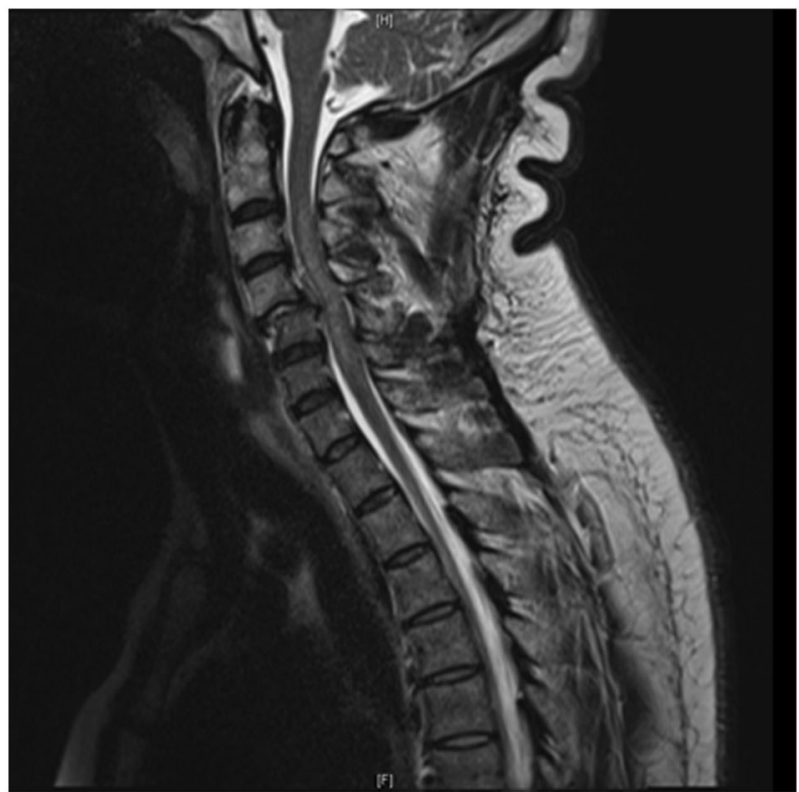

Pre-reduction MRI C-spine

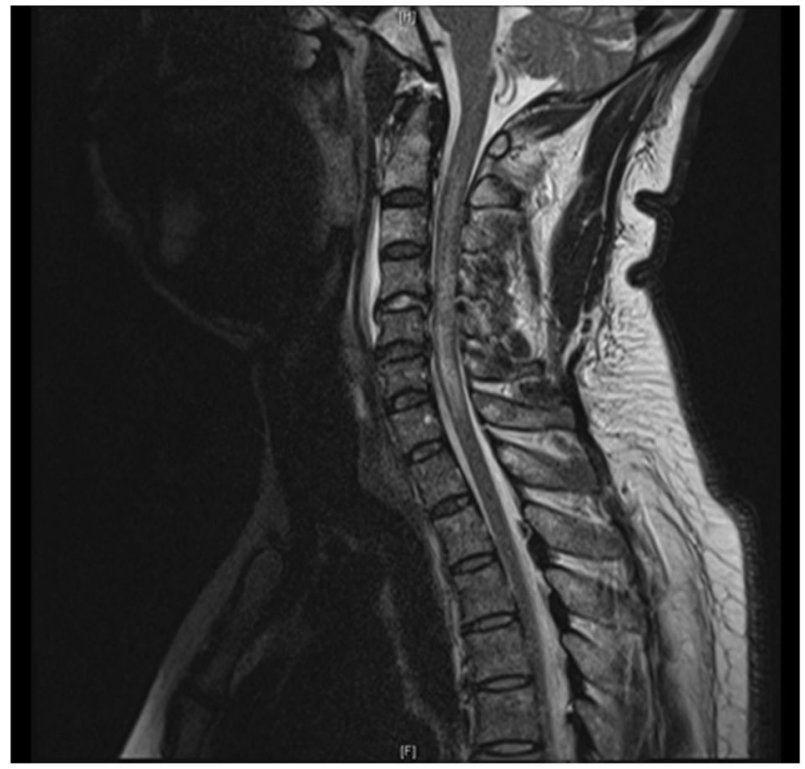

Post-reduction MRI C-spine

Fig. 2 Pre-reduction and post-reduction MRI images of patient A

patients had posterior open reducrtion and internal fixation (ORIF) and ACDF using plate and screws (four patients had the two procedures in one session and two patients had the two procedures in two sessions). Of the remaining three patients, one had ACDF using plate and screws; one had corpectomy with bone graft and fixation and one had posterior ORIF with bone graft. Of the seven patients who remained alive at discharge, three patients improved by one grade in the AIS [Table 2]. Seventy-eight percent of this group improved in their discharge MIS [Fig. 5]. Four patients improved by one motor level and one by two motor levels at discharge.

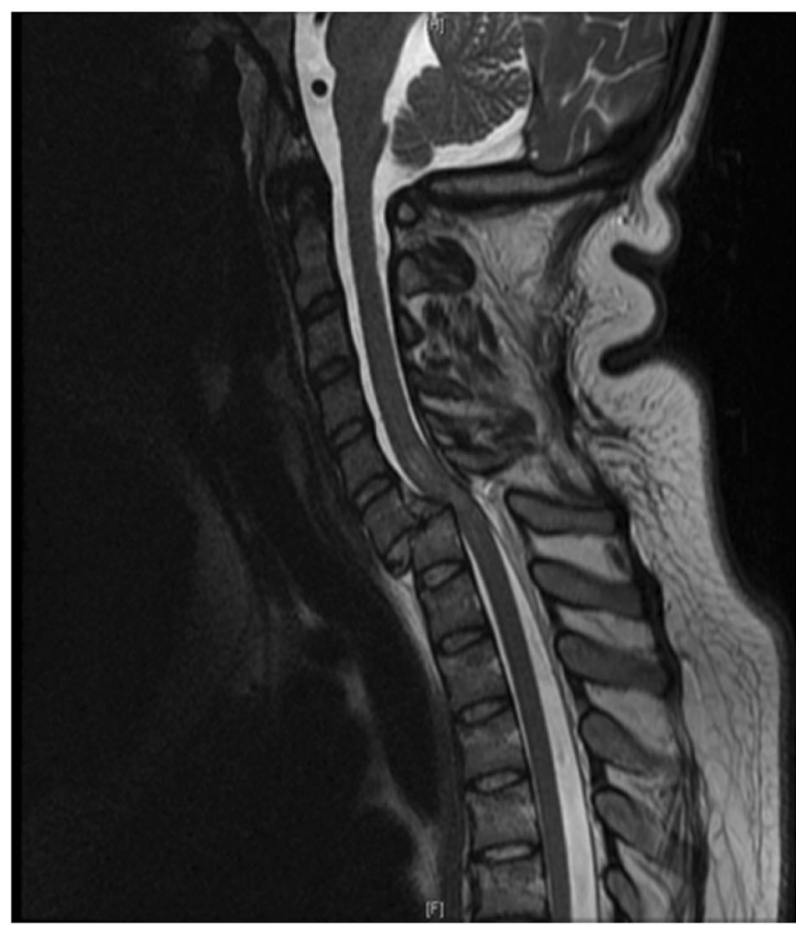

Pre-reduction MRI C-spine

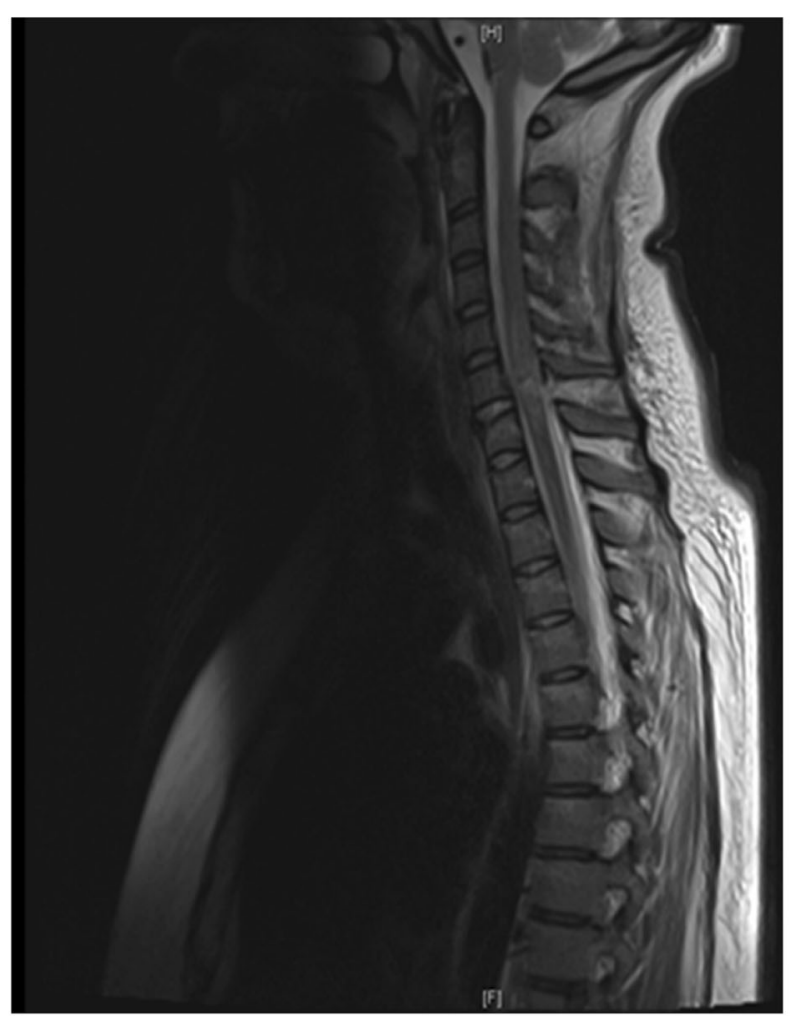

Post-reduction MRI C-spine

Fig. 3 Pre-reduction and post-reduction MRI images of patient B

One patient suffered ascending neurological deficit (lost three motor levels from $\mathrm{C} 7$ to $\mathrm{C} 4$ ) around $14 \mathrm{~h}$ post RICTR. This neurological deterioration was not related to the 


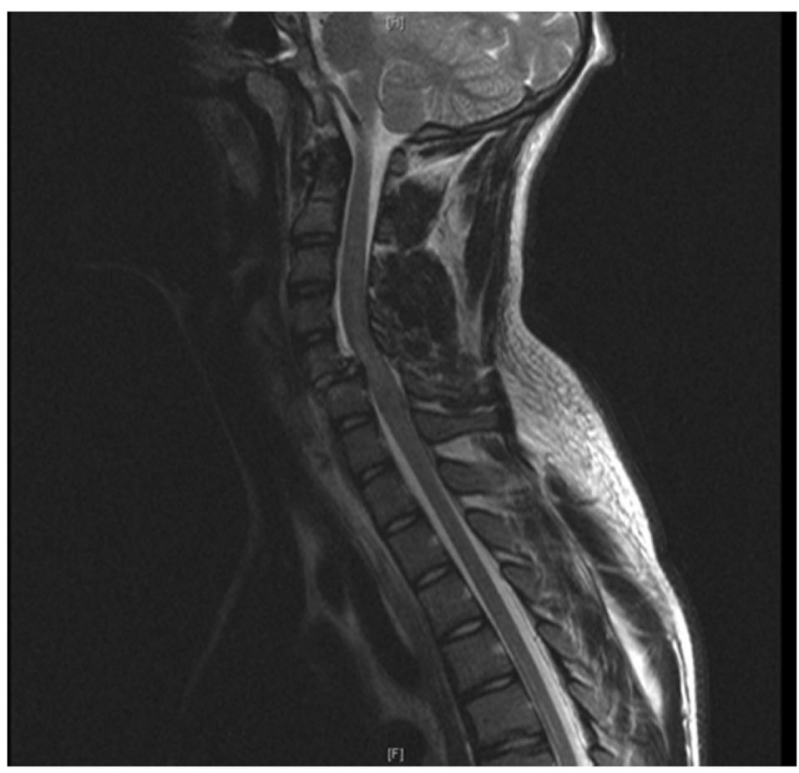

Pre-reduction MRI C-spine

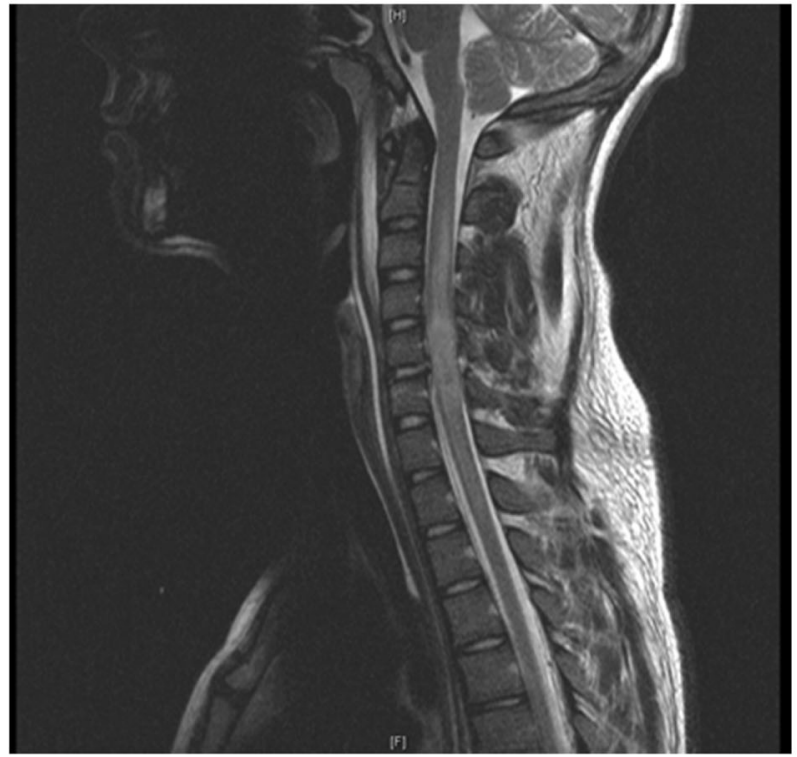

Post-reduction MRI C-spine

Fig. 4 Pre-reduction and post-reduction MRI images of patient $\mathrm{C}$

RICTR as neurological examination during and immediately after the procedure did not show any changes. Subsequently, she developed type II respiratory failure $24 \mathrm{~h}$ post RICTR. Eventually, she became ventilation-dependent and died 3 months later following asystole arrest [Fig. 5]. She had C7/T1 bi-facet dislocation and her past medical history included Scheuermann's disease and asthma. Another patient died in the acute stage ( 9 days post injury); he required intubation 3 days following $\mathrm{ACDF}$ and died following ventricular tachycardia arrest 5 days later.

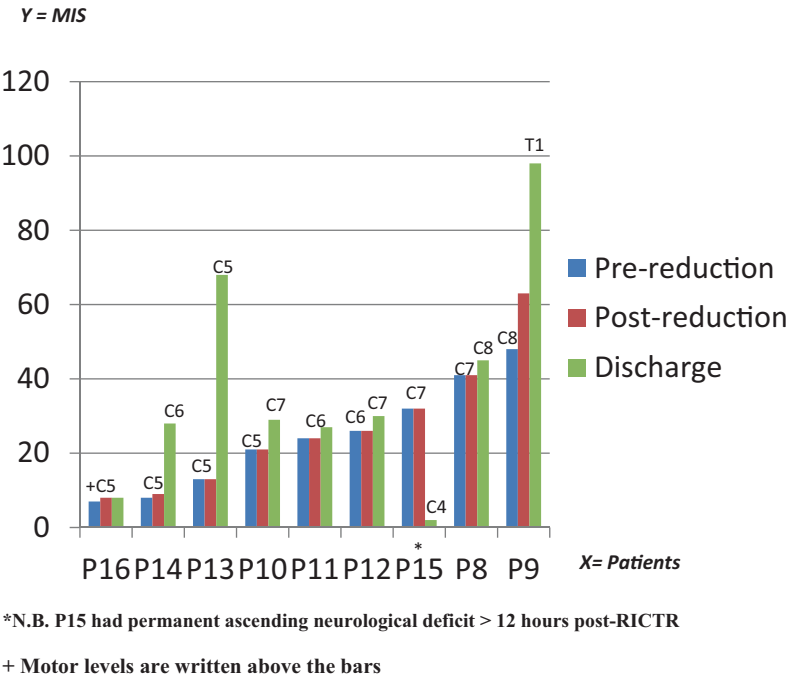

Fig. 5 Pre-reduction, post-reduction and discharge motor index scores (MIS) and motor levels of unsuccessful RICTR group. *N.B. P15 had permanent ascending neurological deficit $>12 \mathrm{~h}$ post RICTR. + Motor levels are written above the bars

\section{Discussion}

A recent systematic review [13] concluded that closed traction reduction in an awake and alert patient is safe and effective with a reported success rate of $80 \%$. The reported incidence of permanent neurologic complications after closed reduction was approximately $1 \%$, whereas transient injury occurred in 2-4\% [13]. This review included papers reporting both techniques of closed reduction; traction reduction and MUA. The effectives of RICTR could be demonstrated at its maximum by complete recovery from paralysis in some studies. Newton et al. [14] demonstrated that RICTR of cervical dislocation, within $4 \mathrm{~h}$ of injury, is important in determining the desired outcome with delays longer than this being associated with a poor outcome. They reported that five out of eight patients, who had successful traction reduction within $4 \mathrm{~h}$ of injury, made a full recovery from complete paralysis. Their study population included patients with cervical dislocations due to rugby accidents causing SCI, which indicated that they sustained a lowvelocity, primary, mechanical injury favouring better outcomes.

Our study showed that RICTR was successful in only $44 \%$ with around $6 \%$ risk of developing a transient neurological deficit. A possible explanation for our less favourable results is that $83 \%$ of RICTR attempts were done $10 \mathrm{~h}$ or later post injury. In fact, $80 \%$ of the RICTR attempts past the $30 \mathrm{~h}$ mark post injury ended in failure and the resulting transient and permanent neurological deficits were at 18 and $30 \mathrm{~h}$ post injury, respectively. This is because at least seven cases were transferred late (1-2 days post injury) to our 
tertiary centre from distant parts of the UK. Comparison of the mean time to reduction between the successful and unsuccessful RICTR groups [Table 1] might be misleading because, by excluding one patient who had his successful second RICTR attempt at $90 \mathrm{~h}$, the mean drops to $13 \mathrm{~h}$. That is to say the mean time to reduction of the unsuccessful RICTR group is almost double that of the successful RICTR group. It is widely known that reflex cervical muscles contractions can complicate cervical dislocations and impede reduction despite using muscle relaxants. Another possible factor is the type and level of injury as all the bifacet $\mathrm{C} 7 / \mathrm{T} 1$ dislocation cases failed RICTR attempts, including one case that ended with permanent neurological deficit. In one patient there was pre-existing congenital C4-C6 fusion and another had Sheuermann's disease, both of which could have possibly contributed to their failed RICTR attempts. The only case during which the traction cord snapped failed RICTR, which suggests equipment failure as an additional factor. The only case of permanent ascending neurological deficit was coincidental and happened more than $12 \mathrm{~h}$ post RICTR. The two deaths (due to ventricular tachycardia and asystole), from the unsuccessful RICTR group, were not related to the procedure.

On the other hand, significant improvements in the postRICTR and discharge MIS and motor levels were recorded following successful RICTR. However, the fact that more than half of the cases resulted from motor vehicle accidents suggesting high energy trauma would certainly affect the neurological outcomes.

The newly developed Singhal Traction Bed (http:// closedreduction.co.nz/wp-content/uploads/2016/05/Singha 1-protocol.pdf) uses a load cell tensioner handle to produce incremental traction with simultaneous flexion of the cervical spine. With a reportedly close to $90 \%$ success rate of RICTR [15] the wide use of the Singhal Traction Bed will certainly increase the average success rate of the procedure and subsequently minimise the risk of neurological deficits. In their 22 cases of successful RICTR reported, the average weight used was only $13.5 \mathrm{~kg}$ with average reduction time of $29 \mathrm{~min}$ from the start of the procedure.

Our study was limited by the fact that it was a retrospective, case series, single-centre study. The small number $(n=16)$ of included patients added a risk of attrition bias. The age range was narrow limiting the applicability of the results in older patients.

In conclusion, our RICTR success rate was lower than the average success rate of $70-80 \%$ as reported in the literature. This was largely affected by the significant delays in admission and RICTR attempts, in addition to other confounding factors such as congenital spinal conditions and equipment failure. RICTR procedures are no longer performed in the NSIC because most (if not all) cervical fracture dislocation cases are currently treated in MTC. In those MTC, where a trained spinal surgeon and $24 \mathrm{~h}$ emergency theatre are available, RICTR may be reliably performed in emergency departments. Furthermore, we recommend that the procedure is done within $4 \mathrm{~h}$ of injury as the literature evidence suggests that complete recovery from paralysis could be possible, especially in scenarios of low-energy trauma such as rugby injuries, if the procedure is performed within $4 \mathrm{~h}$ of injury [14]. Even if complete recovery is not possible, considerable improvements in the neurological level of injury, MIS and AIS grade would almost certainly achieve functional gains for those who remain with residual neurological deficit. Finally, we also recommend conducting a large-scale prospective multi-centre study to determine the clinical and costeffectiveness of RICTR, within $4 \mathrm{~h}$ of sustaining a cervical dislocation resulting in SCI, using the Singhal Traction Bed (prior to ORIF) in comparison with operative reduction and fixation (without RICTR).

Acknowledgements We would like to express our deep gratitude and special thanks to the late Mr. Dennis Newton-Consultant Orthopaedic and Spinal Surgeon-who introduced the concept of RICTR into the practice of the National Spinal Injuries Centre in 2006.

Author contributions WA has contributed to the study design, data collection, data analysis, drafting and revising the manuscript, approving the final version and taking accountability of all aspects of the work. AN has contributed to the study design, data collection, revising the manuscript, approving the final version and taking accountability of all aspects of the work. MB has contributed to the study design, data collection, revising the manuscript, approving the final version and taking accountability of all aspects of the work.

\section{Compliance with ethical standards}

Conflict of interest The authors declare that they have no conflict of interest.

\section{References}

1. Vaccaro AR, Falatyn SP, Flanders AE, Balderston RA, Northrup $\mathrm{BE}$, Cotler JM. Magnetic resonance evaluation of the intervertebral disc, spinal ligaments, and spinal cord before and after closed traction reduction of cervical spine dislocations. Spine. 1999;24:1210-7.

2. Lee JY, Nassr A, Eck JC, Vaccaro AR. Controversies in the treatment of cervical spine dislocations. Spine J. 2009;9:418-23.

3. Hadley MN, Fitzpatrick BC, Sonntag VKH, Browner CM, Dacey RG Jr. Facet fracture-dislocation injuries of the cervical spine. Neurosurgery. 1992;30:661-6.

4. Rowland JW, Hawryluk GW, Kown B, Fehlings MG. Current status of acute spinal cord injury pathophysiology and emerging therapies: promise on the horizon. Neurosurg Focus. 2008;25:E2.

5. Norrell ET,H. The treatment of unstable spinal fractures and dislocations. Clin Neurosurg. 1978;25:193.

6. O'Brien PJ, Schweigel JF, Thompson WJ. Dislocations of the lower cervical spine. J Trauma Inj Infect Crit Care. 1982;22:710-4. 
7. Sabiston CP, Wing PC, Schweigel JF, van Peteghem PK, Yu W. Closed reduction of dislocations of the lower cervical spine. $\mathrm{J}$ Trauma Inj Infect Crit Care. 1988;28:832-5.

8. Cotler HB, Miller LS, Delucia FA, Cotler JM, Davne SH. Closed reduction of cervical spine dislocations. Clinical Orthopaedics and Related Research. 1987;214:185-99.

9. Osti OL, Fraser RD, Griffiths ER. Reduction and stabilization of cervical dislocations. An analysis of 167 cases. J Bone Joint Surg Br. 1989;71-B:275-82.

10. Star AM, Jones AA, Cotler JM, Balderston RA, Sinha R. Immediate closed reduction of cervical spine dislocations using traction. Spine. 1990;15:1068-72.

11. Lee AS, Maclean JC, Newton DA. Rapid traction for reduction of cervical spine dislocations. J Bone Joint Surg Br. 1994;76:352-6.

12. Marino RJ, Barros T, Biering-Sorensen F, Burns SP, Donovan WH, Graves DEETAL. International standards for neurological classification of spinal cord injury. J Spinal Cord Med. 2003;26 (Suppl 1):S50-6.

13. Gleb DE, Hadley MN, Arabi B, Dhall SS, Hurlbert RJ, Rozzelle $\mathrm{CJ}$, et al. Initial closed reduction of cervical spinal fracturedislocation injuries. Neurosurgery. 2013;72:73-83.

14. Newton D, England M, Doll H, Gardner BP. The case for early treatment of dislocations of the cervical spine with cord involvement sustained playing rugby. $\mathrm{J}$ Bone Joint Surg $\mathrm{Br}$. 2011;93:1646-52.

15. Newton D, Gardner B, England M \& Singhal B. Low velocity spinal cord injury with dislocation, the England national approach to the prevention of the secondary injury, using rugby as an example. International Spinal Cord Injury Society Conference 2012 program \& abstracts book, ISCoS 2012. p. 94-95. http://www.iscos.org.uk/sitefiles/ISCoS-programme-20.pdf. Accessed on 30 May 2018. 